\title{
Serum and salivary enzymes - possible indicator of the incidence of tooth decay in patients with chronic alcoholic hepatitis
}

\author{
Lecturer Daniela G. BALAN ${ }^{1}$, MD, Phd, Univ. Assist. Iulia I. STANESCU ${ }^{1}$, MD, PhD, \\ Univ. Assist. Andra E. BALCANGIU-STROESCU ${ }^{1}, \mathrm{MD}$, PhD, Drd. Dr. Adela M. CEAU ${ }^{2}, \mathrm{MD}$, \\ ${ }^{1}$ Physiology Department, Faculty of Dental Medicine, \\ University of Medicine and Pharmacy "Carol Davila", Bucharest \\ ${ }^{2}$ Politehnica University, Bucharest \\ ${ }^{3}$ Physiopathology and Immunology Department, Faculty of Dental Medicine, \\ University of Medicine and Pharmacy "Carol Davila", Bucharest
} Lecturer Alexandru G. CROITORU ${ }^{3}$, MD, PhD, Univ. Assist. Dan PIPEREA-SIANU ${ }^{1}$, MD, PhD candidate

\begin{abstract}
Objectives. Determination of correlations between the cariogenic index, as quantifying element for the frequency of tooth decay, and some salivary and serum enzymes in patients who had been diagnosed with chronic alcoholic hepatitis.

Materials and methods. The study group consisted of 25 patients diagnosed with chronic alcoholic hepatitis. The following salivary enzymes were determined: AST, ALT and the AST/ALT ratio. Also, the following plasma enzymes were determined: AST, ALT, amylase, LDH, GGT, ALP, AST/ALT and GGT/ALP ratios.

Results. The determined average values were: cariogenic index $1,8 \pm 0,96$, salivary AST 72,52 $446,21 \mathrm{U} / \mathrm{L}$,

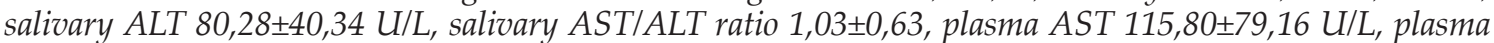

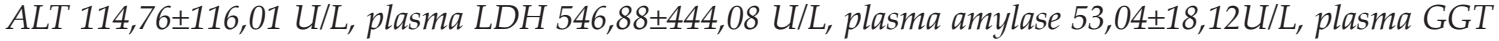

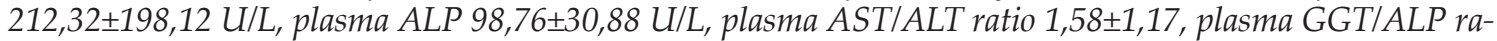
tio $2,15 \pm 1,76$.

Conclusions. Statistically significant correlations were determined between the cariogenic index and the salivary AST/ALT ratio, plasma AST, plasma ALT, plasma AST/ALT ratio.
\end{abstract}

Keywords: chronic alcoholic hepatitis, cariogenic index, salivary enzymes, plasma enzymes

\section{INTRODUCTION}

Ethylic alcohol is an organic compound that affects the specific and non-specific defense mechanisms of the oral cavity as well as the integrity of oral structures. For this reason, people with high-level alcohol consumption have a modified oral status characterized by an increased incidence of dental caries, compared to non-alcoholic individuals. The increased inci- dence of tooth decay is due, on the one hand, to the denaturing action of ethylic alcohol, and, on the other hand, to the poor oral hygiene and general malnourishment in these individuals (1).

Alcoholic hepatitis is a liver inflammatory syndrome that occurs in people who consume alcohol in excess for many years, but the relationship between alcohol consumption, the amount, the duration of consumption, the type

\section{Corresponding author:}

Univ. Assist. Dan Piperea-Sianu, PhD candidate, Physiology Department, Faculty of Dental Medicine, „Carol Davila” University of Medicine and Pharmacy, 8th Eroii Sanitari Blvd, Bucharest, Romania

E-mail: sianu.dan@gmail.com 
of alcohol consumed and the occurrence of liver disease is complex. Not all the individuals who consume large quantities of alcohol develop hepatopathy, but alcoholic hepatitis may occur in people who consume alcohol moderately (2).

According to the World Health Organization, around 3.3 million deaths are reported globally as a consequence of excessive alcohol consumption. It also mentions an average alcohol consumption of 6.2 liters of alcohol per person, aged at least 15 . Alcoholism is therefore considered a major health problem, which must be rapidly diagnosed in order to prevent side effects and in order to limit the socio-economic impact (3).

\section{OBJECTIVES}

Through the present study we aimed to determine the correlations between the frequency of tooth decay, objectified through the cariogenic index $(\mathrm{Cl})$, and a series of salivary and plasma enzymes in individuals diagnosed with chronic alcoholic hepatitis.

It is common knowledge that some serum parameters are useful for screening, diagnosing and following the evolution of the aforementioned patients. Some of these parameters are gamma-glutamyltransferase (GGT), alanine aminotransferase (ALT), aspartate aminotransferase (AST), AST/ALT ratio.

Saliva is a fluid that is increasingly used to dose constituents whose variation may be useful for the diagnosis of various oral and systemic conditions. Among the advantages of saliva samples vs. blood samples, we can mention: lower costs, taking saliva samples is easier than taking plasma samples, patients are much more likely to accept getting saliva samples repeatedly.

\section{MATERIALS AND METHODS}

The study was conducted on 25 patients ( 23 males and 2 females), averagely aged $41.16 \pm$ 7.93 , investigated both clinically and paraclinically, diagnosed with chronic alcoholic hepatitis.

In order to confirm the diagnosis and also to exclude the viral etiology of the hepatic impairment, the following seric determinations were made: anti-VHA IgM, anti-HBc IgM, AgHBs, AgH$\mathrm{Be}$, anti-HBe, anti-HBc, anti-VHC antibodies. The patients with chronic alcoholic hepatitis had a common history of chronic alcohol consumption, negative viral markers, symptoms and results of paraclinical investigations suggesting hepatic impairment.
Blood and saliva samples were taken in the morning (8:30-9:30), à jeun, the patients having not eaten at least 12 hours before. The blood samples were taken through venous punction, and were processed in the hospital laboratory, using standard techniques for preparing the samples for the investigation.

Regarding saliva, at least 120 minutes before the sampling, the patients had to brush their teeth, being known that even in the case of minor lesions, like the ones that can occur during brushing, the plasma exsudate may modify the salivary composition. No other oral hygiene manouvers were allowed. Patients were not allowed to drink, eat, smoke or make any physical effort after brushing their teeth, before the sampling. 60 minutes before sampling, the patients rinsed their oral cavities with distilled water. 15-20 minutes after the venous punction, mixed saliva samples were taken - the secretion of saliva should not have been stimulated. The samples were taken in sterile callibrated test tubes, held in ice-cold environment. The sampling was conducted for 10 minutes, at 1 minute intervals (the first saliva sample was not used). The patients were sitted in a relaxed position and were asked not to swallow during the sampling.

The status of the oral cavity was objectified by examination of teeth and soft tissues. The absent teeth as well and the teeth affected by tooth decay (treated or not) were identified and counted. The result was written down as cariogenic index. " + " signifies 4 carious lesions or less, "++" signifies between 4 and 10 carious lesions and "+++" signifies more than 10 carious lesions.

From the saliva samples the following parameters were determined: aspartate aminotransferase (AST), alanine aminotransferase (ALT), AST/ALT ratio.

From the blood samples the following parameters were determined: aspartate aminotransferase (AST), alanine aminotransferase (ALT), AST/ALT ratio, lactate dehydrogenase (LDH), amylase, gamma-glutamyltransferase (GGT), alkaline phosphatase (ALP), GGT/ALP ratio.

\section{RESULTS AND DISCUSSIONS}

Table 1 presents the salivary concentrations of AST, ALT and salivary AST/ALT ratio in the patients from the study group, together with their average values and standard deviations. The av- 
erage values that were determined are: salivary AST $72.52 \pm 46.21 \mathrm{U} / \mathrm{L}$, salivary ALT $80.28 \pm$ $40.34 \mathrm{U} / \mathrm{L}$, salivary AST/ALT ratio $1.03 \pm 0.63$.

TABLE 1. Cariogenic index values and salivary enzymes concentrations

\begin{tabular}{|c|c|c|c|c|}
\hline Patient & $\begin{array}{c}\text { Cariogenic } \\
\text { index }\end{array}$ & $\begin{array}{l}\text { Salivary } \\
\text { AST U/L }\end{array}$ & \begin{tabular}{|l|} 
Salivary \\
ALT U/L \\
\end{tabular} & $\begin{array}{c}\text { Salivary } \\
\text { AST/ALT ratio }\end{array}$ \\
\hline $1 \mathrm{~F}$ & 3 & 150 & 126 & 1.19 \\
\hline $2 M$ & 0 & 39 & 82 & 0.48 \\
\hline $3 M$ & 2 & 31 & 44 & 0.70 \\
\hline $4 M$ & 3 & 136 & 150 & 0.91 \\
\hline $5 \mathrm{M}$ & 1 & 76 & 38 & 2.00 \\
\hline $6 \mathrm{M}$ & 2 & 45 & 47 & 0.96 \\
\hline $7 \mathrm{M}$ & 3 & 69 & 53 & 1.30 \\
\hline $8 \mathrm{M}$ & 3 & 32 & 134 & 0.24 \\
\hline $9 M$ & 1 & 45 & 33 & 1.36 \\
\hline $10 \mathrm{~F}$ & 1 & 86 & 49 & 1.76 \\
\hline $11 \mathrm{M}$ & 2 & 92 & 32 & 2.88 \\
\hline $12 \mathrm{M}$ & 3 & 213 & 110 & 1.94 \\
\hline $13 \mathrm{M}$ & 2 & 47 & 57 & 0.82 \\
\hline $14 \mathrm{M}$ & 1 & 22 & 74 & 0.30 \\
\hline $15 \mathrm{M}$ & 1 & 68 & 106 & 0.64 \\
\hline $16 \mathrm{M}$ & 2 & 92 & 54 & 1.70 \\
\hline $17 \mathrm{M}$ & 3 & 42 & 94 & 0.45 \\
\hline $18 \mathrm{M}$ & 1 & 37 & 86 & 0.43 \\
\hline $19 M$ & 2 & 48 & 116 & 0.41 \\
\hline $20 \mathrm{M}$ & 2 & 79 & 70 & 1.13 \\
\hline $21 \mathrm{M}$ & 2 & 35 & 47 & 0.74 \\
\hline $22 \mathrm{M}$ & 0 & 46 & 65 & 0.71 \\
\hline $23 \mathrm{M}$ & 3 & 98 & 142 & 0.69 \\
\hline $24 \mathrm{M}$ & 1 & 43 & 34 & 1.26 \\
\hline $25 \mathrm{M}$ & 1 & 142 & 164 & 0.87 \\
\hline av.val. & 1.80 & 72.52 & 80.28 & 1.03 \\
\hline st.dev. & 0.96 & 46.21 & 40.34 & 0.63 \\
\hline
\end{tabular}

Table 2 presents the $p$ values, which represent the statistical correlation between the cariogenic index and the analysed salivary parameters. No statistically significant correlations were determined between the cariogenic index and salivary AST $(p=0.406)$ or salivary ALT $(p=$ 0.401).

TABLE 2. The statistical signification (p) of the correlation between the cariogenic index and the salivary concentrations of AST, ALT and salivary AST/ALT ratio

\begin{tabular}{|c|c|c|c|}
\hline & Salivary AST & Salivary ALT & AST/ALT Ratio \\
\hline $\begin{array}{c}\text { Correlation } \\
\text { with Cl }\end{array}$ & 0.406 & 0.401 & 0.045 \\
\hline
\end{tabular}

Statistically significant correlations $(p<0.05$ ) were determined between the cariogenic index and the AST/ALT ratio ( $p=0.045$ ) (Fig. 1). The literature mentions the correlation between salivary AST and ALT and plasmatic AST and ALT values in patients with chronic hepatopathy, including in patients with alcoholic hepatitis (4-6). Moreover, Dalai C et al mention the increase in salivary AST and ALT in pregnant women with tooth decay and gingival impairment. (7).
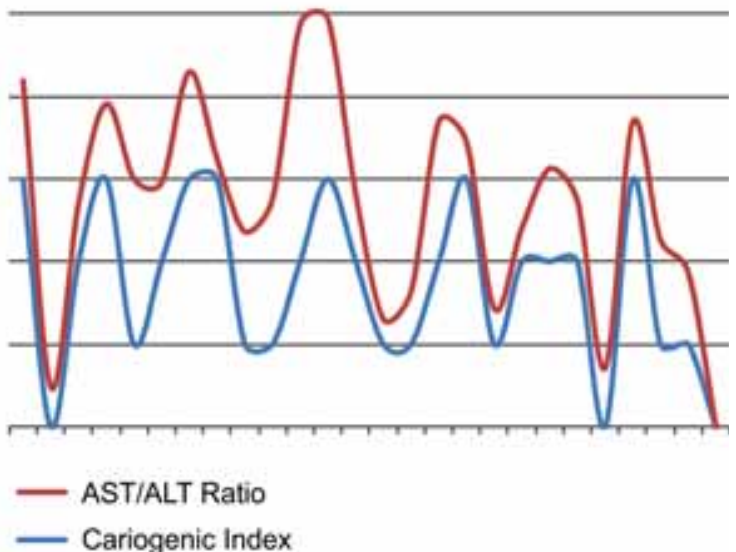

FIGURE 1. Graphic representation of the statistically significant correlation between $\mathrm{Cl}$ and salivary AST/ALT ratio

Table 3 presents the values of the seric concentrations of aspartate aminotransferase (AST), alanine aminotransferase (ALT), AST/ALT ratio, lactate dehydrogenase (LDH), seric amylase, gamma-glutamyltransferase (GGT), alkaline phosphatase (ALP), GGT/ALP ratio in the patients from the study group, together with their average values and standard deviations.

The determined average values are: plasma aspartate aminotransferase $115.8 \pm 79.16 \mathrm{U} / \mathrm{L}$, plasma alanine aminotransferase $114.76 \pm$ $116.01 \mathrm{U} / \mathrm{L}, \mathrm{AST} / \mathrm{ALT}$ ratio $1.58 \pm 1.17, \mathrm{LDH}$ $546.88 \pm 444.08 \mathrm{U} / \mathrm{L}$, amylase $53.04 \pm 18.12 \mathrm{U} / \mathrm{L}$, GGT $212.32 \pm 198.85 \mathrm{U} / \mathrm{L}, \mathrm{ALP} 93.76 \pm 30.88 \mathrm{U} / \mathrm{L}$, GGT/ALP ratio $2.15 \pm 1.76$.

Table 4 presents the $p$ values, which represent the statistical significance of the correlation between the cariogenic index and the plasma concentrations of AST, ALT, AST/ALT ratio, LDH, amylase, GGT, ALP and GGT/ALP ratio. Statistically significant correlations were not determined between the cariogenic index and LDH ( $p=0.386)$, plasma amylase $(p=0.387)$, GGT $(p=0.411)$, alkaline phosphatase $(p=0.216)$ and GGT/ALP ratio ( $p=0.375)$.

Regarding aspartate aminotransferase ( $p=$ $0.046)$, alanine aminotransferase $(p=0.027)$ and 
TABLE 3. Plasma enzymes concentrations

\begin{tabular}{|c|c|c|c|c|c|c|c|c|}
\hline Patient & $\begin{array}{l}\text { AST } \\
\text { U/L }\end{array}$ & $\begin{array}{l}\text { ALT } \\
\text { U/L }\end{array}$ & $\begin{array}{c}\text { AST/ALT } \\
\text { Ratio }\end{array}$ & $\begin{array}{l}\text { LDH } \\
\mathrm{U} / \mathrm{L}\end{array}$ & Amylase U/L & $\begin{array}{l}\text { GGT } \\
\text { U/L }\end{array}$ & $\begin{array}{l}\text { ALP } \\
U / L\end{array}$ & $\begin{array}{c}\text { GGT/ALP } \\
\text { Ratio }\end{array}$ \\
\hline $1 \mathrm{~F}$ & 52 & 132 & 0.39 & 1989 & 84 & 516 & 131 & 3.939 \\
\hline $2 \mathrm{M}$ & 74 & 90 & 0.82 & 215 & 57 & 137 & 91 & 1.505 \\
\hline $3 M$ & 69 & 278 & 0.25 & 336 & 42 & 161 & 61 & 2.639 \\
\hline $4 \mathrm{M}$ & 294 & 250 & 1.18 & 282 & 84 & 100 & 100 & 1.000 \\
\hline $5 M$ & 109 & 48 & 2.27 & 206 & 52 & 55 & 77 & 0.714 \\
\hline $6 M$ & 126 & 24 & 5.25 & 158 & 61 & 53 & 101 & 0.525 \\
\hline $7 \mathrm{M}$ & 134 & 45 & 2.98 & 1128 & 69 & 517 & 139 & 3.719 \\
\hline $8 \mathrm{M}$ & 121 & 209 & 0.58 & 874 & 69 & 519 & 98 & 5.296 \\
\hline $9 M$ & 29 & 31 & 0.94 & 263 & 36 & 60 & 124 & 0.484 \\
\hline $10 \mathrm{~F}$ & 73 & 20 & 3.65 & 148 & 39 & 15 & 47 & 0.319 \\
\hline $11 \mathrm{M}$ & 82 & 44 & 1.86 & 226 & 45 & 31 & 63 & 0.492 \\
\hline $12 \mathrm{M}$ & 124 & 54 & 2.30 & 1213 & 33 & 654 & 183 & 3.574 \\
\hline $13 \mathrm{M}$ & 39 & 22 & 1.77 & 227 & 32 & 47 & 76 & 0.618 \\
\hline $14 \mathrm{M}$ & 194 & 224 & 0.76 & 997 & 30 & 603 & 88 & 6.852 \\
\hline $15 \mathrm{M}$ & 95 & 112 & 0.85 & 573 & 56 & 111 & 103 & 1.078 \\
\hline $16 \mathrm{M}$ & 147 & 123 & 1.20 & 342 & 42 & 51 & 72 & 0.708 \\
\hline $17 \mathrm{M}$ & 52 & 94 & 0.55 & 486 & 66 & 217 & 49 & 4.429 \\
\hline $18 \mathrm{M}$ & 179 & 173 & 1.03 & 442 & 31 & 154 & 83 & 1.855 \\
\hline $19 M$ & 77 & 33 & 2.33 & 239 & 30 & 41 & 97 & 0.423 \\
\hline $20 M$ & 46 & 29 & 1.59 & 264 & 78 & 205 & 70 & 2.929 \\
\hline $21 \mathrm{M}$ & 154 & 63 & 2.44 & 422 & 80 & 241 & 96 & 2.510 \\
\hline $22 \mathrm{M}$ & 78 & 36 & 2.17 & 553 & 51 & 117 & 74 & 1.581 \\
\hline $23 M$ & 140 & 119 & 1.18 & 970 & - & 374 & 99 & 3.778 \\
\hline $24 M$ & 31 & 40 & 0.78 & 245 & 53 & 67 & 85 & 0.788 \\
\hline $25 \mathrm{M}$ & 366 & 536 & 0.68 & 874 & - & 262 & 137 & 1.912 \\
\hline av.val. & 115.80 & 114.76 & 1.58 & 546.88 & 53.04 & 212.32 & 93.76 & 2.15 \\
\hline st.dev. & 79.16 & 116.01 & 1.17 & 444.08 & 18.12 & 198.85 & 30.88 & 1.76 \\
\hline
\end{tabular}

AST/ALT ratio ( $p=-0.042$ ), we observed statistically significant correlations with the cariogenic index in patients with alcoholic hepatitis (Fig. 2).

Shivashankara AR et al., in a study conducted on 50 chronic alcoholics with history over the previous 5 years, analyzed the correlation between AST, ALT and serum and saliva GGT before and after alcohol withdrawal. The serum enzyme activity was significantly higher com- pared to the control group. Serum concentrations for GGT, ALT and AST were 4.4, 2, and 1.8 times higher, respectively, compared to the control group. Enzyme concentration decreased significantly one month after alcohol withdrawal. They concluded that there is a statistically significant correlation between alcohol consumption and the seric but also salivary concentration of these enzymes (6).

TABLE 4. The statistical significance (p) of the correlation between the cariogenic index and the plasma concentrations of AST, ALT, AST/ALT ratio, LDH, amylase, GGT, ALP, and GGT/ALP ratio

\begin{tabular}{|c|c|c|c|c|c|c|c|c|}
\hline & AST & ALT & AST/ALT Ratio & LDH & Amyalse & GGT & ALP & GGT/ALP Ratio \\
\hline $\begin{array}{c}\text { Correlation } \\
\text { with Cl }\end{array}$ & 0.049 & 0.027 & -0.042 & 0.386 & 0.387 & 0.411 & 0.216 & 0.375 \\
\hline
\end{tabular}




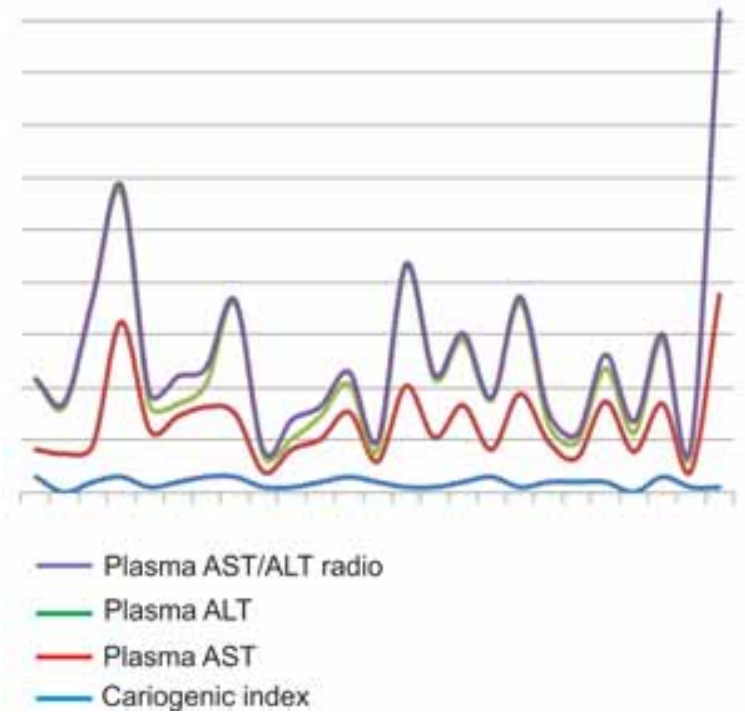

FIGURE 2. Graphic representation of the statistically significant correlations between $\mathrm{Cl}$ and plasma AST/ALT ratio and plasma ALT and AST

\section{CONCLUSIONS}

Following the determinations performed on salivary and plasma enzymes in patients from the chronic alcoholic hepatitis group, we were able to establish statistically significant correlations between the cariogenic index and the following parameters: salivary AST/ALT, plasma AST, plasma ALT and plasma AST/ALT ratio.

The correlations that were determined are in line with the literature studies, conducted on the general population.

In order to perform a correct and complete oral rehabilitation, the clinician, particularly the dental practitioner, needs to take into account both the systemic context and local elements such as caries risk or prognosis of carious disease. Although not being parameters that are commonly found in blood or saliva, AST and ALT dosing can provide information regarding the risk of tooth decay and its prognosis in patients with chronic alcoholic hepatitis, these being useful for the dentist.

\section{Acknowledgement}

Daniela G. Bălan, Iulia I. Stănescu, Andra E. Stroescu-Balcangiu, Adela M. Ceau, Alexandru G. Croitoru, Dan Piperea-Șianu shared first authorship.

\section{REFERENCES}

1. Kruntz E., Kruntz H.D. Hepatology: Textbook and Atlas, $3^{\text {rd }}$ edition, SpringerVerlag Berlin Heidelberg, 2008, ISBN 978-3-662-49970-2

2. Nash K., Guha I.N. Hepatology: Clinical Cases Uncovered, Wiley-Blackwell, 2011, ISBN 978-1-444-33246-9

3. World Health Organization Fact sheet on Alcohol, Updated in January 2015.

4. Feldman M., Friedman L., Brandt L. Sleisenger and Fordtran's Gastrointestinal and Liver Disease - 2 Volume Set: Pathophysiology, Diagnosis, Management, $10^{\text {th }}$ edition, Elsevier, 2016, ISBN 978-1455746927

5. Schiff E., Maddrey W., Reddy R. Schiff's Diseases of the Liver, 12th Edition, Wiley, 2017, 978-1119251224

6. Shivashankara A.R., Claudia J., Malathi M. A correlative study on the aminotransferases and gammaglutamyltransferase in the saliva and serum of chronic alcoholics before and after Alcohol Deaddiction, JCDR, 2011; 5(3):512-515

7. Dalai C., Bodog F. Salivary and serum modifications of the biochemical parameters in pregnant women with tooth disorders, Acta Medica Transilvanica, 2012; 2(4):302-305 